\title{
Direct detection of acetylene in air by continuous wave cavity ring-down spectroscopy
}

\section{Schmidt, F.}

SPRINGER

2010

Schmidt , F , Vaittinen , O , Metsälä , M , Kraus , P \& Halonen , L 2010 , ' Direct detection of acetylene in air by continuous wave cavity ring-down spectroscopy ' , Applied physics. B, Lasers and optics, Vuosikerta / volyymi 101, Nro 3 , Sivut 671-682.

http://hdl.handle.net/10138/24040

http://dx.doi.org/10.1007/s00340-010-4027-5

Downloaded from Helda, University of Helsinki institutional repository.

This is an electronic reprint of the original article.

This reprint may differ from the original in pagination and typographic detail.

Please cite the original version. 


\title{
Direct detection of acetylene in air by continuous wave cavity ring-down spectroscopy
}

\author{
F.M. Schmidt • O. Vaittinen • M. Metsälä • P. Kraus • \\ L. Halonen
}

Received: 25 February 2010 / Revised version: 24 March 2010 / Published online: 6 May 2010

(C) Springer-Verlag 2010

\begin{abstract}
Diode laser-based continuous wave cavity ringdown spectroscopy (cw-CRDS) in the near-infrared region has been used to measure the mixing ratio of acetylene $\left(\mathrm{C}_{2} \mathrm{H}_{2}\right)$ in ambient air. Detection limits of 120 parts per trillion by volume (pptv) for $20 \mathrm{~min}$ and $340 \mathrm{pptv}$ for $70 \mathrm{~s}$ acquisition time were achieved without sample pre-concentration, measuring on a $\mathrm{C}_{2} \mathrm{H}_{2}$ absorption line at $6565.620 \mathrm{~cm}^{-1}(\sim 1523 \mathrm{~nm})$. Several indoor and outdoor air samples were collected at different locations in the Helsinki metropolitan area and analyzed using static-cell measurements. In addition, flow measurements of indoor and outdoor air have been performed continuously over several days with a time resolution of down to one minute. Baseline acetylene levels in the range of 0.4 to 3 parts per billion by volume (ppbv), with a maximum around midday and a minimum during the night, were measured. Sudden high mixing ratios of up to $60 \mathrm{ppbv}$ were observed in outdoor air during daytime on a minute time scale. In general, the indoor mixing ratios were found to be higher than those in outdoor air. The acetylene levels correlated with the ambient CO levels and with outdoor temperature.
\end{abstract}

\section{Introduction}

Acetylene $\left(\mathrm{C}_{2} \mathrm{H}_{2}\right)$ is one of the most common hydrocarbons in the troposphere [1-3] originating almost exclusively from anthropogenic sources [4]. It is a regular product of combustion processes, mainly present in vehicle exhausts (fossil

F.M. Schmidt · O. Vaittinen · M. Metsälä · P. Kraus ·

L. Halonen $(\varangle)$

Laboratory of Physical Chemistry, Department of Chemistry, University of Helsinki, A.I. Virtasen aukio 1, P.O. Box 55, 00014

Helsinki, Finland

e-mail: lauri.halonen@ helsinki.fi fuels and biofuels) but also caused by biomass burning [5]. The acetylene mixing ratios in outdoor air are usually above one part per billion by volume (ppbv) in populated urban areas $[1-3,6,7]$ and below that value in rural settings $[4,5$, $8,9]$. Tropospheric acetylene mixing ratios also show a distinctive annual pattern with wintertime values 2 to 10 times higher than summertime recordings $[5,6,10]$.

While volatile organic compounds (VOCs) and nitrogen oxides $\left(\mathrm{NO}_{x}\right)$ are the most important chemical precursors of tropospheric ozone $\left(\mathrm{O}_{3}\right)$ [7], acetylene (a light VOC) is one of the most photochemically unreactive hydrocarbon species with almost negligible contribution to ozone formation [3, 7]. As with other hydrocarbons, it is mainly removed from the atmosphere by a reaction with the hydroxyl radical $(\mathrm{OH})$. However, acetylene has a relatively long local atmospheric lifetime of about two weeks [5]. The compound can thus be employed as a marker for anthropogenic emissions and to trace polluted air masses. Furthermore, it is common to use VOC/acetylene ratios in atmospheric investigations to identify VOC sources other than combustion $[2,3]$. Such ratios are also helpful in evaluating the impact of vehicle exhausts on the seasonal variation of the total VOC concentration [8,9]. Since acetylene is highly correlated with another combustion marker, carbon monoxide (CO), the $\mathrm{C}_{2} \mathrm{H}_{2} / \mathrm{CO}$ concentration ratio can be used as a tracer of chemical aging and dilution of polluted air [5, 10]. In addition to environmental and atmospheric studies, the measurement of acetylene mixing ratios is important in industrial applications, such as the petrochemical industry, where acetylene is an impurity in ethylene gas flows [11, 12]. Many of the applications mentioned above require fast acetylene concentration measurements with high sensitivity, accuracy and selectivity.

The standard analytical technique for the quantification of trace volatile hydrocarbons in atmospheric samples is gas 
chromatography combined with mass spectrometry (GCMS). This highly sensitive and reliable method is routinely used to simultaneously measure multiple VOCs at down to parts per trillion by volume (pptv) levels [13]. The high sensitivity can, however, only be achieved by pre-concentration of the collected air sample, which takes time and requires large sample volumes. Moreover, a GC-MS instrument must be frequently calibrated using standard gas mixtures. The calibration and pre-concentration procedures together with the chromatographic separation stage are time-consuming, resulting in acquisition times of tens of minutes up to several hours. This makes real-time monitoring of trace volatile compounds in the atmosphere or in industrial gas flows impossible. Some of these drawbacks have been overcome in proton-transfer reaction mass spectrometry (PTR-MS), which allows fast detection of VOCs at sub-ppbv levels [13, 14]. However, acetylene cannot be detected with this method due to its unfavorable proton affinity [13].

The detection of light gas phase molecules in trace concentrations is an established field of application of laserbased absorption spectroscopy [15]. Monochromatic laser radiation inherently provides selectivity between the absorption lines of different compounds without the need for a separation stage. Widely tunable lasers allow many species to be detected with the same experimental setup. Absorption spectrometers based on diode lasers can be made compact and portable, thus enabling in situ trace gas detection for atmospheric measurements and in industrial applications. The required ppbv to pptv sensitivity levels are often achieved by employing an external optical cavity with high reflectivity mirrors as a sample cell, thereby enhancing the effective absorption path length and thus the absorption signal [16]. Several cavity-enhanced techniques have been employed to develop instruments for sensitive $\mathrm{C}_{2} \mathrm{H}_{2}$ measurements [11, 12, 17-24].

One of the most common cavity-enhanced absorption techniques for highly sensitive trace gas detection is cavity ring-down spectroscopy (CRDS) [25, 26]. The CRDS signal is independent of laser intensity fluctuations, and calibration procedures are not required if the line strength of the molecular transition is known. Various implementations of the technique are employed in fields such as atmospheric chemistry, medical diagnostics and combustion research [26]. In a recent study, Pradhan et al. used a near-infrared continuous wave CRDS (cw-CRDS) diode laser spectrometer to measure acetylene mixing ratios in ambient air [23, 24]. For automated measurements at 30 minutes intervals they achieved a detection limit of 35 pptv by 10 -fold sample pre-concentration using an adsorbent trap [24]. The preconcentration process reduces spectral interference through selective adsorption on the trap and enables low detection limits, but it requires additional components in the gas sampling stage and leads to a relatively long total acquisition time.
In this work, we present a cw-CRDS setup based on an external cavity diode laser operating in the near-infrared region that allowed us to measure typical acetylene mixing ratios in air without the need for sample pre-concentration. A number of outdoor and indoor air samples, collected into gas sampling bags around the Helsinki metropolitan area, were analyzed in static-cell measurements. To reveal diurnal changes and short-term fluctuations in the mixing ratio of acetylene, we also performed continuous on-line measurements over 24 hour cycles by applying a constant flow of outdoor or indoor air through the CRDS cavity. Furthermore, the amount of acetylene in the exhaled breath of a human being was measured.

\section{Experimental setup and procedures}

\subsection{Cavity ring-down setup}

The CRDS setup used in this study is similar to the original cw-CRDS apparatus described in [25]. A schematic diagram of the setup is shown in Fig. 1. An external cavity diode laser (ECDL) (New Focus, Velocity 6328), tunable between $6350 \mathrm{~cm}^{-1}$ and $6575 \mathrm{~cm}^{-1}$, was used as the near-infrared light source. The laser output power was about $20 \mathrm{~mW}$, and the optical bandwidth was $\sim 1 \mathrm{MHz}$. A small fraction of the laser power was directed to a wavemeter (EXFO, WA-1500), which had a specified uncertainty of $\pm 40 \mathrm{MHz}$. The main part of the laser beam was passed through an optical isolator (OI) (OFR, IO-2.5-1554-VLP) and then focused into an acousto-optical modulator (AOM) (Brimrose, AMM-80), which was connected to an $80 \mathrm{MHz}$ RF driver (Brimrose, FFA-80). The AOM was used as a fast optical switch and the first order beam was utilized in the ring-down experiment. The beam was then directed through a mode-matching telescope that optimized the beam properties to match the lowest transverse electro-magnetic mode $\left(\mathrm{TEM}_{00}\right)$ of the ring-down cavity (RDC). An InGaAs photo receiver (RedWavelabs, D100) was used to detect the light transmitted through the optical resonator. A home-made comparator switch monitored the signal from the detector and turned off the AOM once a certain intensity of the laser light had been coupled into the RDC. The signal from the detector was also sent to a personal computer equipped with a fast 12-bit data acquisition card (Gage, Compuscope 12100). The ringdown decays were then digitized and fitted to a single exponential function using the Levenberg-Marquadt algorithm [27] in a LabVIEW (National Instruments) program. The same software controlled the tuning of the laser frequency during the scans. The laser frequency was scanned over the spectral window once in a stepwise fashion with an interval of about $90 \mathrm{MHz}$.

The RDC (Los Gatos Research, Inc.) was made of stainless steel and the internal surfaces were coated with quartz 
Fig. 1 Schematic diagram of the experimental setup. $\mathrm{ECDL}=$ external cavity diode laser; OI = optical isolator;

$\mathrm{BS}=$ beamsplitter;

$\mathrm{AOM}=$ acousto-optic modulator; $\mathrm{V}=$ valve; $\mathrm{MFC}=$ mass flow controller

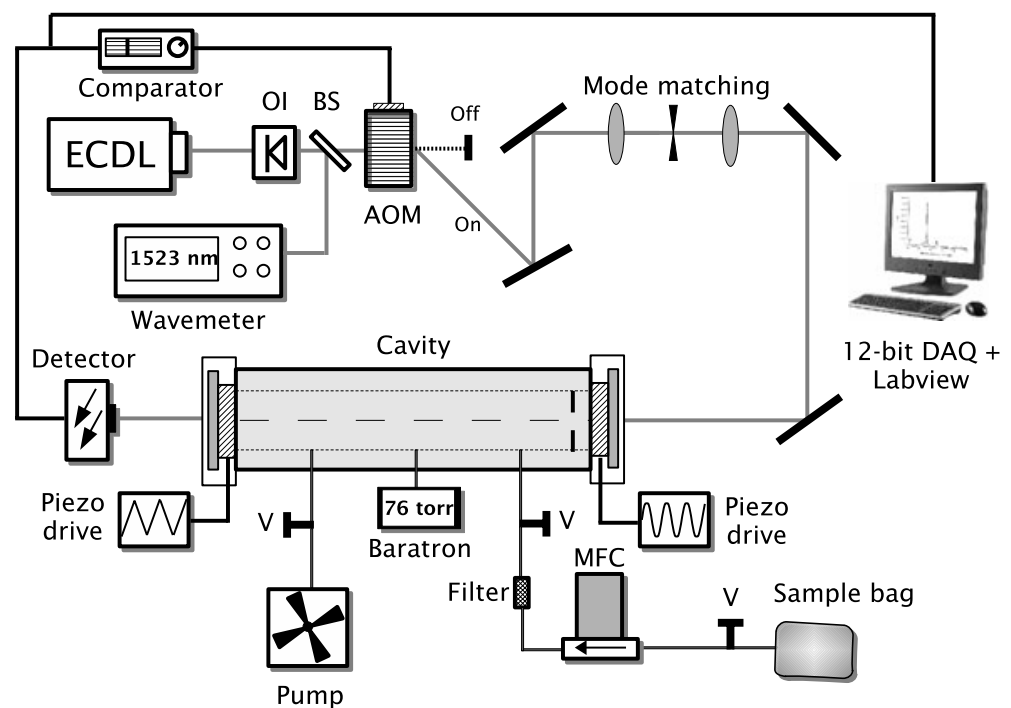

to produce a chemically non-reactive surface. The total sample volume of the cell was $0.5 \mathrm{dm}^{3}$. The mirrors (Layertec $\mathrm{GmbH}$, specified transmission coefficient at $1560 \mathrm{~nm} T \sim$ $0.001 \%$ ) were placed $517 \mathrm{~mm}$ apart, thus creating an optical resonator with a free spectral range (FSR) of $290 \mathrm{MHz}$. The empty cavity ring-down time was $215 \mu$ s, which corresponds to an optical finesse of about 390000 . The radius of curvature of both mirrors was $1 \mathrm{~m}$ and the rear surfaces of the mirrors were anti-reflection coated. A mirror purge system was not used. To enable $\mathrm{TEM}_{00}$ excitation at all laser wavelengths the back mirror of the cavity was placed in a mirror mount with three piezo-actuated mounting screws. The piezos were used to modulate the cavity length by an amount that corresponded to approximately one cavity FSR. The modulation had a saw-tooth shape and a frequency of $30 \mathrm{~Hz}$, thus allowing a repetition rate of $60 \mathrm{~Hz}$ for the ringdown decays.

The ring-down time was slightly different for different positions (voltages) of the piezos used to modulate the cavity length. As the laser frequency was scanned, the different piezo positions were periodically sampled and a corresponding saw-tooth shaped background signal was observed in the recorded spectra. Even by optimizing the gains and offsets applied to the three piezos, we were unable to reduce this periodic background variation. The same type of background signal was also described in [28], where the authors applied mechanical vibrations to the setup to randomize (and average out) the modulation. In a similar approach, we used a ring-type piezo to apply a slow $(2 \mathrm{~Hz})$ sine-wave modulation (of about one FSR) to the front mirror of the cavity. As the phase-shift between this sine-wave and the saw-tooth applied to the back mirror was not fixed, we were able to randomize the periodic background for time scales larger than $\sim 1$ s. The averaging of ring-down decays and spectra then reduced the magnitude of the saw-tooth background signal. Another type of noise we observed as we tuned the cavity length were sudden drops in the cavity decay time, which originated from the coupling of the $\mathrm{TEM}_{00}$ mode with higher order transverse cavity modes. The coupling mechanism is described in detail in [29], where it is suggested to place an aperture inside the cavity to limit the excitation of the higher order transverse modes. After insertion of a $\varnothing 4 \mathrm{~mm}$ intra-cavity aperture, the sudden decay time drops were completely eliminated from the spectra.

The sensitivity of the spectrometer can be estimated from the baseline noise of the ring-down time constant $\tau$. The reciprocal of $\tau$ is the ring-down rate coefficient $k$ and changes in the rate coefficient $\Delta k$ are directly related to the molecular absorption coefficient $\alpha$ by $\Delta k=c \alpha$, where $c$ is the speed of light. The molecular absorption coefficient is, in turn, proportional to the number density of molecules $n$ [molecules $\mathrm{cm}^{-3}$ ] and the frequency-dependent absorption cross section $S\left[\mathrm{~cm}^{2}\right]$ by $\alpha=S n$. The minimum detectable absorption coefficient, $\alpha_{\min }$, is determined by the minimum detectable change in the time decay, which can be defined as the value of the standard deviation $(\sigma)$ of a statistically significant number of baseline points in the spectrum. The minimum detectable absorption can then be expressed as [26]

$\alpha_{\min }=\frac{1}{c}\left(\frac{1}{\tau_{0}-\sigma_{0}}-\frac{1}{\tau_{0}}\right)$,

where $\tau_{0}$ refers to the time constant in the absence of molecular absorption. A typical noise-equivalent detection limit for the CRDS setup used in this study was $7 \times 10^{-11} \mathrm{~cm}^{-1}$. This was achieved without background subtraction for a single scan recorded by averaging 100 ring-down decays per point at an acquisition rate of $60 \mathrm{~Hz}$. In principle, it would be possible to further optimize the sensitivity in terms of the noise in the ring-down time constant, i.e to find the optimal averaging time for our setup and identify and reduce the 
dominant noise sources. However, the factors limiting our sensitivity for acetylene mixing ratio measurements are currently not associated with the ring-down time constant itself but are related to air sampling procedures and spectral interference due to other molecular absorbers such as carbon dioxide $\left(\mathrm{CO}_{2}\right)$, ammonia $\left(\mathrm{NH}_{3}\right)$ and water $\left(\mathrm{H}_{2} \mathrm{O}\right)$. The detection limits for acetylene were thus deduced from actual sample spectra by curve fitting, as described in Sect. 3.1.

\subsection{Sample handling}

The air samples were injected into the RDC either from an aluminum-coated sampling bag of $1.3 \mathrm{dm}^{3}$ volume (Wagner Analysen Technik, WT 8004) or directly from the indoor/outdoor air. The bags were filled in about $30 \mathrm{~s}$ using an air sampling pump (SKC 224-PCXR4). A rotary vane pump (Edwards, RV3) equipped with a liquid nitrogen trap was used to transfer the samples to the gas line. A Baratron pressure gauge (MKS, 622A12) was connected to the RDC to monitor the absolute pressure in the cavity. Before each static measurement, the RDC was flushed with ambient air for about 5 minutes. For flow measurements, a mass flow controller (MFC) (MKS, M100B) was used to control the flow rate of the gas supplied to the cavity. The flow rate was kept at approximately $2 \mathrm{dm}^{3} / \mathrm{min}$ for most measurements, resulting in a residence time of the air in the cavity of $\sim 3 \mathrm{~s}$. A filter (Swagelok, SS-6TF-MM-05) was installed in the gas line to block particulate matter $>0.5 \mu \mathrm{m}$ by diameter.

To be able to make quantitative gas mixing ratio measurements, the adsorption/desorption properties of the molecule of interest must be investigated. For highly reactive molecules, like ammonia and formaldehyde, this is a major problem and static-cell measurements are usually not appropriate. Fortunately, acetylene is fairly non-reactive and adsorption to surfaces of our apparatus was negligible. The same acetylene mixing ratios were retrieved whether the measurement was done in static-cell or flow conditions. Flow measurements were thus used only for continuous indoor/outdoor air sampling. To establish the measurement error when using the bags, ten sampling bags were filled with ambient laboratory air and analyzed immediately, resulting in a mean mixing ratio of $0.47 \pm 0.04 \mathrm{ppbv}$, where the error refers to one standard deviation. We also followed the evolution of the acetylene mixing ratio in a sampling bag for the duration of several days. The acetylene level remained within 40 pptv for 5 days. Most of our samples were analyzed within 2 days from collection; at most they were in the bags for 3 days. The particulate filter at the inlet of the cavity did not influence the acetylene mixing ratios; ammonia and water levels were, however, significantly lower when the filter was employed. As mentioned above, the RDC was manufactured from silica coated stainless steel, and the gas tubings were all made of either stainless steel or polytetrafluoroethylene (PTFE).
The optimum pressure for quantitative spectroscopy is a compromise between signal strength and overlap between neighboring absorption lines. As the pressure is increased, the number density of molecules goes up but, at the same time, pressure broadening spreads the line intensity over a wider frequency range. The wings of close lying peaks (of $\mathrm{CO}_{2}, \mathrm{H}_{2} \mathrm{O}$ etc.) then start to overlap with the peak of interest. To establish the optimum pressure for our experiment, we recorded spectra in the pressure range of 30-100 Torr around the selected acetylene peak. A pressure of 76 Torr $(0.1 \mathrm{~atm})$ was chosen as a reasonable compromise. At this pressure, the full width at half maximum (FWHM) of the Doppler profile $\left(0.016 \mathrm{~cm}^{-1}\right)$ is comparable to the pressure broadening (FWHM $\sim 0.018 \mathrm{~cm}^{-1}$ ) as obtained from the HITRAN database [30]. Consequently, this pressure was used for all the measurements presented in this study, both in static and in flow conditions.

The apparatus was not temperature stabilized. Thus, the sample temperature was assumed to be room temperature, about $22^{\circ} \mathrm{C}(295 \mathrm{~K})$. Small changes in the room temperature $\left( \pm 0.5^{\circ} \mathrm{C}\right)$ were possible but this had only a minor $(\sim 1 \%)$ effect on the retrieved acetylene mixing ratios. This was the case for all measurements where the sample was either collected in a bag or sampled directly from the laboratory. The situation was different for the flow measurements where the sample was collected from outside the lab window using a long PTFE tube since the temperature outside was up to $25^{\circ} \mathrm{C}$ below room temperature. A definite temperature could not be assigned to these samples; it was between $0-22^{\circ} \mathrm{C}$, depending on how fast the sample equilibrated with the apparatus. If we assume a temperature difference of $10^{\circ} \mathrm{C}$ between the sample and room temperature, based on changes in line intensity and molar volume, we can estimate the recorded acetylene levels to be up to $10 \%$ too low. Additionally, because the pressure in the RDC was not actively stabilized, there were increases in pressure (and thus an overestimation in the $\mathrm{C}_{2} \mathrm{H}_{2}$ mixing ratio) of up to $20 \%$ during the overnight flow measurements. The pressure variations were caused by changes in pumping power of our vacuum system, mainly due to the gradual evaporation of liquid nitrogen from the cold trap between the gas line and the rotary vane pump.

\section{Results}

In this section, we evaluate the performance and capabilities of the described cw-CRDS spectrometer optimized for ambient air acetylene measurements and present the results of wintertime recordings in the Helsinki metropolitan area. In late November and early December 2009, several indoor and outdoor air samples were collected into sampling bags and analyzed in static-cell measurements. During two weeks in 
Fig. 2 Typical spectrum for the static and low time resolution flow measurements. The experimental data points (solid markers) are shown together with a fit (solid line) and the residual of the fit (below). The acetylene mixing ratio determined for this sample (no. 15 , private apartment) was $0.93 \mathrm{ppbv}$

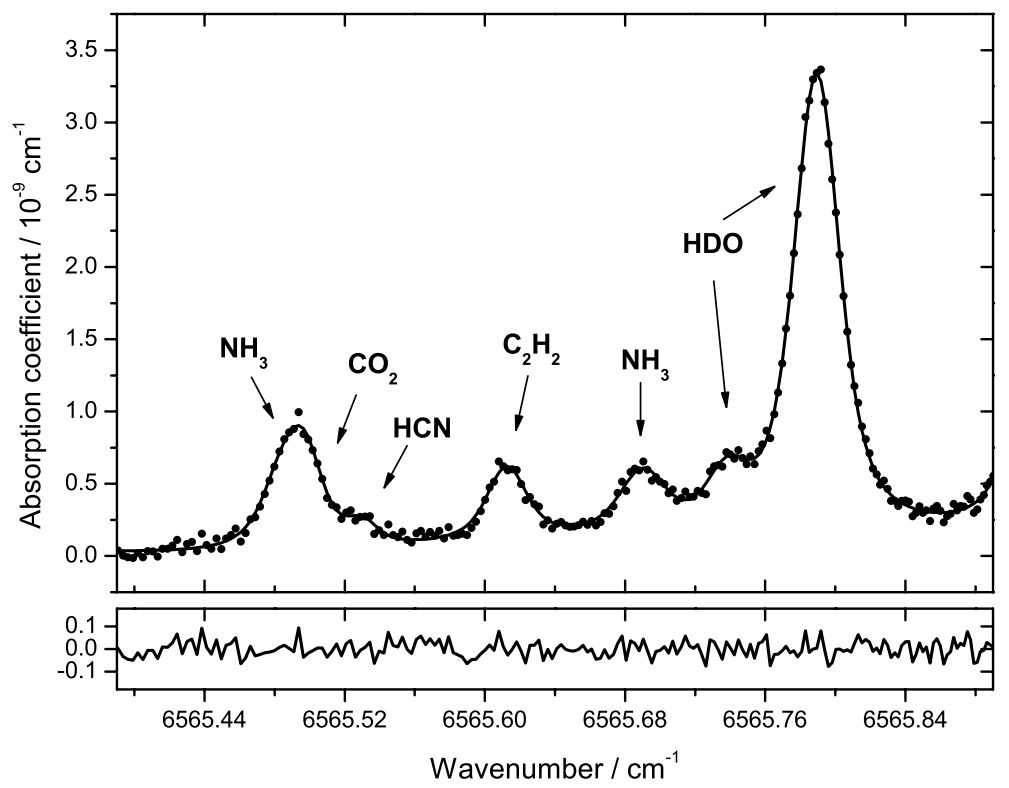

December 2009, continuous flow measurements of both outdoor and indoor air were performed, partly with high time resolution.

\subsection{Spectrometer performance}

Figure 2 shows a typical spectrum of ambient air in the spectral region around the $\mathrm{R}(3)$ acetylene absorption line at $6565.620 \mathrm{~cm}^{-1}$ [30] of the $v_{1}+v_{3}$ vibrational combination band. The line strength of this transition, $8.385 \times$ $10^{-21} \mathrm{~cm} \times$ molecule $^{-1}$ [30], is known with an accuracy of better than $2 \%$ [31]. The displayed spectrum is an average of two consecutive scans each recorded over a time of 10 minutes. Each of the 200 experimental data points (solid markers) corresponds to the average of 100 ring-down events. Apart from the $\mathrm{C}_{2} \mathrm{H}_{2}$ absorption line, peaks of $\mathrm{NH}_{3}\left(6565.496 \mathrm{~cm}^{-1}\right.$ and $6565.692 \mathrm{~cm}^{-1}$ [32]), $\mathrm{CO}_{2}\left(6565.509 \mathrm{~cm}^{-1}\right.$ [30]), hydrogen cyanide $(\mathrm{HCN})$ $\left(6565.532 \mathrm{~cm}^{-1}\right.$ [33]) and heavy water (HDO) (6565.799 $\mathrm{cm}^{-1}$ and $6565.754 \mathrm{~cm}^{-1}$ [28]) were identified in this spectral region. Occasionally, a weak $\mathrm{H}_{2} \mathrm{O}$ line at $6565.501 \mathrm{~cm}^{-1}$ [28] was also observed. Seven Voigt line shapes (solid line) were fitted to the spectrum in Fig. 2 using the peak fitting software Fityk [34]. For the acetylene peak, both the Doppler $\left(0.016 \mathrm{~cm}^{-1}\right)$ and collision $\left(0.018 \mathrm{~cm}^{-1}\right)$ widths were kept fixed, whereas only the Doppler widths were fixed for the other species. A sinusoidal function was included in the fit to account for a weak etalon effect, which probably originated from multiple reflections in the substrate of one of the cavity mirrors. The residual of the fit is shown in the separate window below. All peaks are slightly shifted towards lower wavenumbers because of inaccuracies in the wavemeter calibration, and because the light to the wavemeter was picked off before the AOM, which shifts the wavelength about $80 \mathrm{MHz}\left(0.0027 \mathrm{~cm}^{-1}\right)$.

The types of spectra as shown in Fig. 2 were recorded when analyzing the indoor and outdoor samples collected in the bags, and for the outdoor flow measurements performed from December 7 to December 10, 2009. A spectral range of about $0.6 \mathrm{~cm}^{-1}$ was recorded to obtain a reliable baseline and to account for spectral interference due to nearby peaks. The specific spectrum shown in Fig. 2 (sample no. 15) is representative for the indoor air samples. The spectra of the outdoor air samples were usually less complex due to the lower ammonia mixing ratios in outdoor air. In general, due to adsorption/desorption phenomena in the bags, the gas tubings, the particulate filter and the RDC, the magnitudes of the ammonia and water peaks do not represent the actual mixing ratios of these species in the samples.

The acetylene mixing ratio present in sample no. 15 was 0.93 ppbv. We can estimate the limit of detection (LOD) by comparing the peak height obtained from the fit $(5.1 \times$ $10^{-10} \mathrm{~cm}^{-1}$ ) to the standard deviation of the noise in the residual $\left(3.4 \times 10^{-11} \mathrm{~cm}^{-1}\right)$. This yields a signal-to-noise ratio (SNR) of 15 and thus a LOD $(2 \sigma)$ for acetylene of about 120 pptv. This LOD is in accordance with the error determined earlier for the bag measurements. Without preconcentration, we are thus able to directly measure $\mathrm{C}_{2} \mathrm{H}_{2}$ with a sensitivity sufficient for ambient air mixing ratios at both rural and urban sites.

Starting from 14:00 on December 10, the flow measurements were recorded with a significantly higher time resolution of about $70 \mathrm{~s}$. To achieve this, the spectral range was reduced to $0.2 \mathrm{~cm}^{-1}$ (65 data points), just wide enough to scan across the acetylene transition, and only 25 ring-down events were averaged for each point. A typical spectrum, consisting of a single scan, is shown in Fig. 3. A Voigt line 
Fig. 3 Typical spectrum for the high time resolution flow measurements. The experimental data points (solid markers) are shown together with a fit (solid line) and the residual of the fit (below). The acetylene mixing ratio determined for this scan was $1.71 \mathrm{ppbv}$

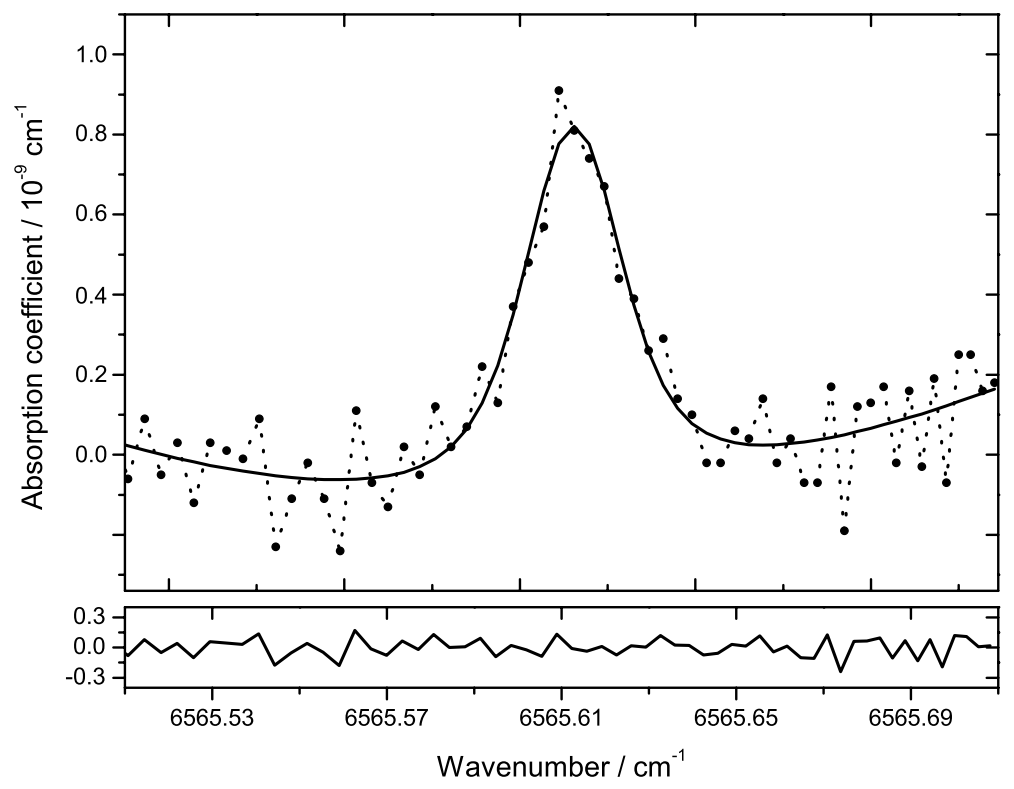

Fig. 4 Measured acetylene mixing ratios (solid markers) as a function of calculated standard mixing ratios in the range of 0.8 to $2000 \mathrm{ppbv}$ (a). The solid line represents a linear least squares fit to the data forced through zero. The inset (b) shows the lowest four data points on a linear scale. The slope of the linear fit is unity

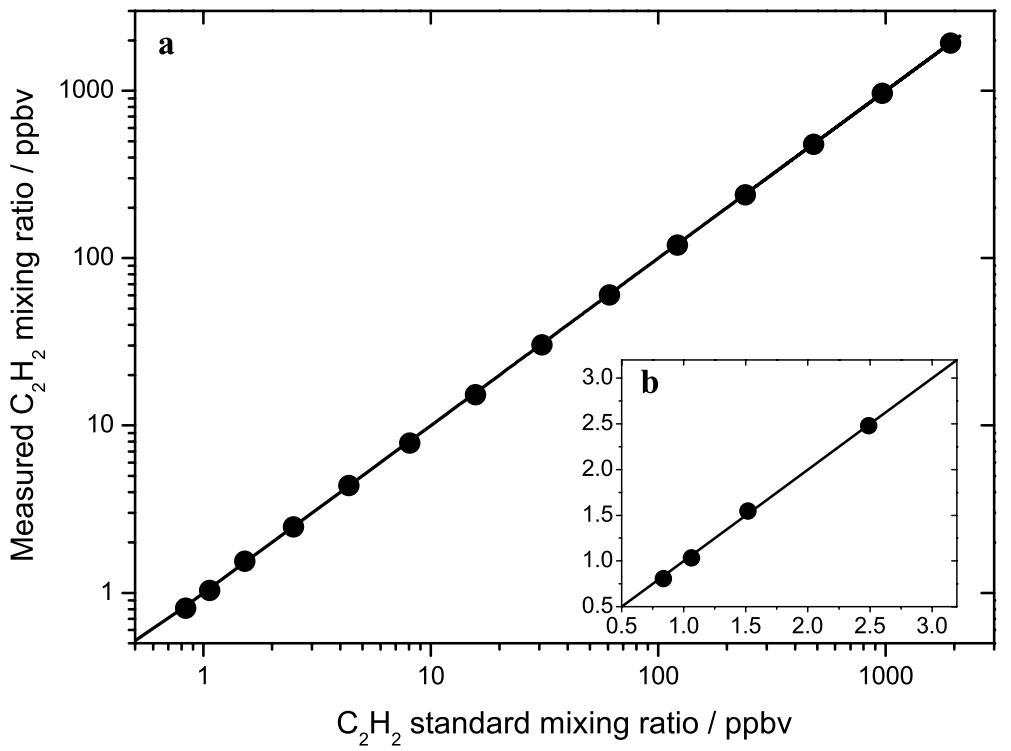

shape and a sinusoidal function (solid line) were fitted to the experimental data points (solid markers), with the Doppler and collision widths kept fixed. The residual of the fit is shown in the separate window below. Since the level of averaging was lower for these spectra, the periodic saw-tooth background signal is more pronounced. The mixing ratio determined for this scan was $1.71 \mathrm{ppbv}$. Again comparing the peak height $\left(9.3 \times 10^{-10} \mathrm{~cm}^{-1}\right)$ with the standard deviation of the noise in the residual $\left(8.8 \times 10^{-11} \mathrm{~cm}^{-1}\right)$, we obtain a SNR of about 10 and thus a LOD $(2 \sigma)$ of 340 pptv, still below the expected ambient air acetylene mixing ratios in Helsinki. Lower mixing ratios than the quoted LOD can probably be fitted given the periodic background signal. Small errors in the fitting of the background due to the narrow wavenumber range and/or contributions from the wings of nearby peaks could have introduced an error in the obtained mixing ratio in the order of tens of ppt.

In order to show the linearity of the cavity ring-down spectrometer for acetylene mixing ratio measurements, a standard of about 2 ppm was prepared and then diluted with ambient air in steps of $50 \%$ down to 0.8 ppbv. In Fig. 4, the measured $\mathrm{C}_{2} \mathrm{H}_{2}$ mixing ratios (solid markers) are plotted against the acetylene standard mixing ratios calculated based on the serial dilution. The ambient air acetylene level at the time of the measurements $(0.6 \mathrm{ppbv})$ was taken into account in the calculation. The solid line shows a linear least squares fit to the data forced through zero. For clarity, the inset (Fig. 4b) displays the lowest 4 points, i.e. the typical indoor/outdoor air mixing ratio range, on a linear scale. As can be seen, the response of the spectrometer is linear over sev- 
Table 1 Outdoor air samples from different locations in the Helsinki metropolitan area collected in winter 2009. Sample number, collection date, collection location and measured acetylene mixing ratio in ppbv are given. Locations are in Helsinki if not otherwise stated. All samples, except samples nos. 7-9, have been collected during daytime, between 9:00 and 15:00

\begin{tabular}{lllll}
\hline No. & Date & Location & ppbv & site \\
\hline 1 & Nov 24 & Suomenlinna & 0.49 & rural \\
2 & Nov 24 & Railway station & 0.50 & urban \\
3 & Nov 24 & Hanasaari power plant & 0.82 & industrial \\
4 & Nov 26 & Airport, Vantaa & 0.37 & industrial \\
5 & Nov 26 & Waste disposal site, Espoo & 0.37 & industrial \\
6 & Nov 26 & Nuuksio National Park, Espoo & 0.71 & rural \\
7 & Dec 1 & Viikki, evening & 0.58 & urban \\
8 & Dec 2 & Viikki, night & 0.40 & urban \\
9 & Dec 2 & Viikki, morning & 0.69 & urban \\
10 & Dec 3 & Kumpula Campus & 0.46 & urban \\
11 & Dec 3 & Kumpula Campus road & 1.88 & urban \\
12 & Dec 3 & Helgträsk, Sipoo & 0.96 & rural \\
13 & Dec 3 & Vuosaari power plant & 0.93 & industrial \\
14 & Dec 3 & Vuosaari harbor & 0.64 & industrial \\
\hline
\end{tabular}

Table 2 Indoor air samples from different locations in Helsinki collected in winter 2009. Sample number, collection date, collection location and measured acetylene mixing ratio in ppbv are given. All samples have been collected during daytime, between 9:00 and 15:00

\begin{tabular}{llll}
\hline No. & Date & Location & ppbv \\
\hline 15 & Nov 15 & Private apartment & 0.93 \\
16 & Nov 20 & Laboratory I & 0.49 \\
17 & Nov 24 & Kamppi shopping center I & 0.60 \\
18 & Nov 24 & Helsinki Cathedral & 0.59 \\
19 & Nov 24 & Public bus I & 0.93 \\
20 & Nov 30 & Laboratory II & 0.69 \\
21 & Dec 2 & Public bus II & 2.05 \\
22 & Dec 2 & Railway station & 0.92 \\
23 & Dec 2 & Kamppi shopping center II & 1.18 \\
24 & Dec 2 & Subway station & 1.41 \\
25 & Dec 2 & Fast food restaurant & 1.32 \\
26 & Dec 2 & Public bus III & 1.81 \\
27 & Dec 2 & Laboratory III & 2.05 \\
28 & Dec 3 & Laboratory IV & 0.51 \\
\hline
\end{tabular}

eral orders of magnitude down to below 1 ppbv. Non-linear effects such as optical saturation were not observed.

\subsection{Outdoor and indoor air samples}

Tables 1 and 2 list a selection of the outdoor and indoor air samples collected in the Helsinki metropolitan area between November 15 and December 4, 2009. Sample number, lo- cation, collection date and the measured acetylene mixing ratio are given. The samples are listed in the order of collection date. The measurement error in the obtained acetylene mixing ratios is $0.12 \mathrm{ppbv}$. The outdoor samples can roughly be divided into being collected at rural (samples nos. 1, 6 and 12), urban (samples nos. 2, 7-11) and industrial (samples nos. 3-5, 13 and 14) sites. The indoor air samples have all been collected at locations close to downtown Helsinki. All samples, except samples nos. 7-9, were collected during daytime, between 9:00 and 15:00. In addition to the ambient air samples, a human breath sample was also analyzed. The acetylene mixing ratio measured in the exhaled breath of a healthy individual $(0.71 \mathrm{ppbv})$ was within the measurement error of the $\mathrm{C}_{2} \mathrm{H}_{2}$ mixing ratio in the laboratory air (sample no. 20, 0.69 ppbv), measured immediately after collection of the breath sample.

\subsection{Time resolved measurements}

Figure 5 presents the outdoor air mixing ratio of acetylene measured with our cw-CRDS spectrometer from December 7 to December 11, 2009 (Fig. 5c), along with the CO mixing ratio (Fig. 5b) and the outdoor temperature (Fig. 5a) in Helsinki during this time period. The time resolution of the measurements performed from 10:00 on Monday, December 7 to $15: 00$ on Thursday, December 10 was 15-20 minutes, whereas the remaining part, from 15:00 on Thursday, December 10 to 18:00 on Friday, December 11 was recorded with an acquisition time of $70 \mathrm{~s}$ per point. The two short interruptions on December 8 and December 9 were necessary for system maintenance. The air was collected with a $5 \mathrm{~m}$ long PTFE tube from outside the laboratory window, $10 \mathrm{~m}$ above ground and $1.5 \mathrm{~m}$ away from the building. The temperature and $\mathrm{CO}$ data (one point per minute) were measured at the SMEAR III research station, located in the Kumpula Campus area, next to our laboratory [35]. The three high peaks recorded around 06:30 on December 9 and around 06:30 and 09:30 on December 10 were distorted because the acetylene mixing ratio changed during the relatively slow scan across the acetylene peak, and thus could not be fitted properly. These three peaks were probably as high as the one recorded with short acquisition time around 07:00 on December 11. The latter peak represents a mixing ratio of $58 \mathrm{ppbv}$, and is not entirely shown (off-scale) in the figure. In general, when considering the results from the outdoor air flow measurements, the errors due to temperature and pressure changes given in Sect. 2.2 and possible errors introduced by the fitting process have to be taken into account.

To clearly show the difference between the level of fluctuations occurring during daytime and during the night, Fig. 6 presents a 4 hour daytime (Fig. 6a) and a 4 hour night-time (Fig. 6b) section of the outdoor flow measurements recorded 
Fig. 5 Outdoor air acetylene mixing ratio in Helsinki measured continuously from Monday, December 7 to Friday, December 11, $2009(\mathbf{c})$, together with the carbon monoxide mixing ratio (b) and the outdoor temperature in Helsinki (a) for the same time period

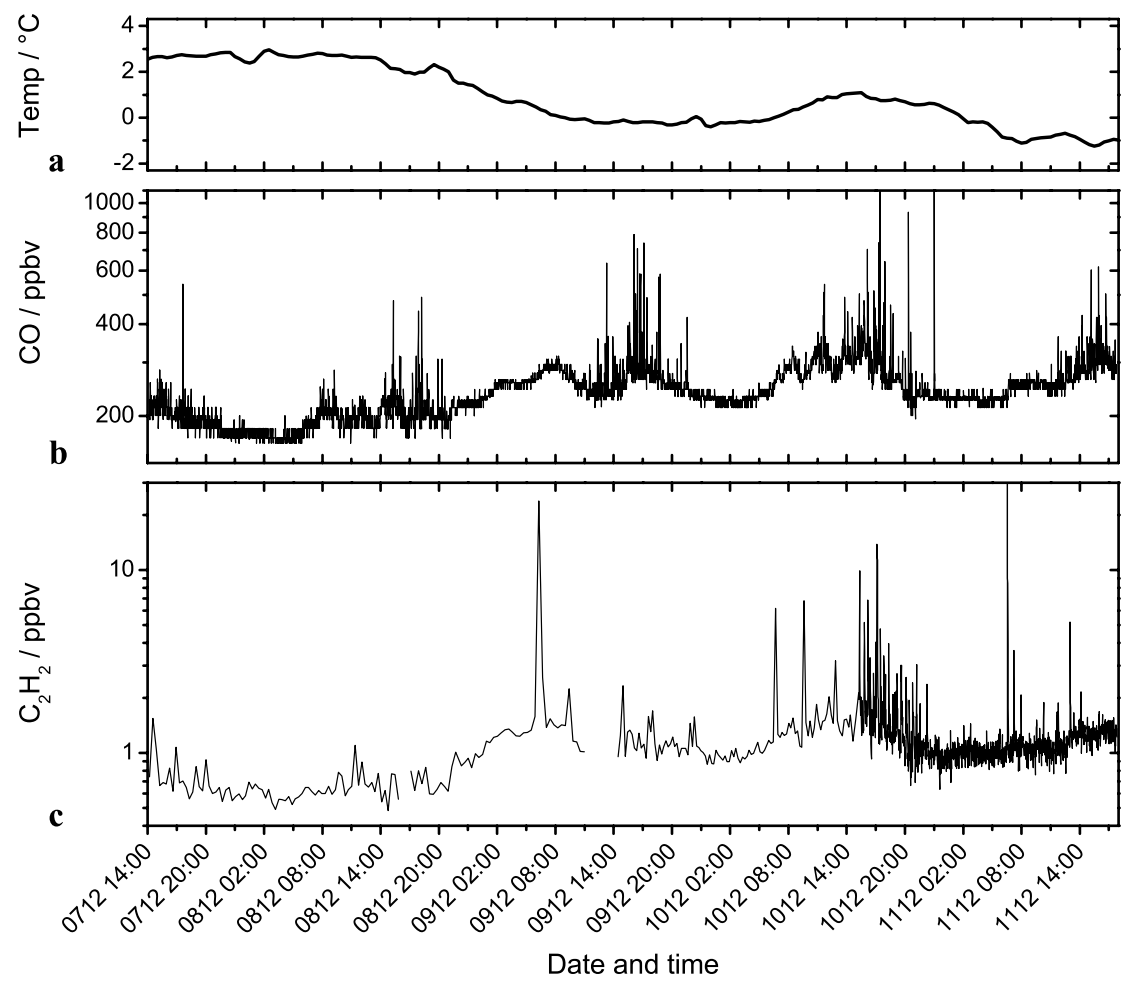

Fig. 6 Outdoor air acetylene mixing ratio in Helsinki measured with $\sim 70$ s time resolution over 4 hours during daytime on Thursday,

December 10, 2009 (a), and over 4 hours during the night on Friday, December 11, 2009 (b)

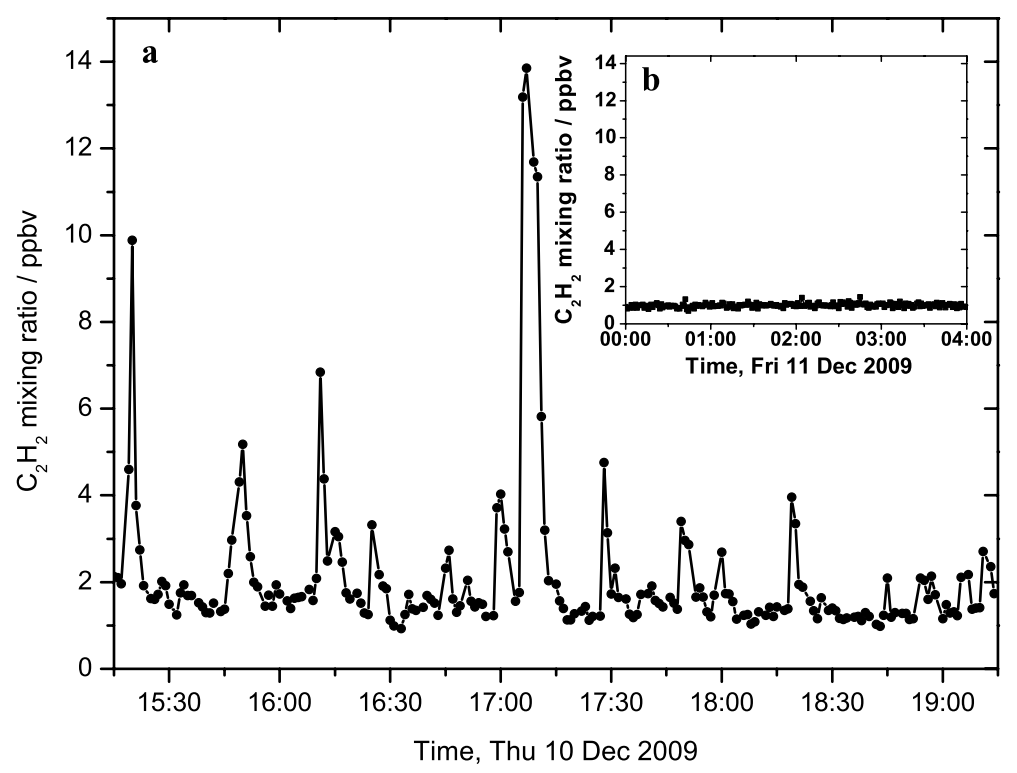

with high time resolution. The main figure displays data from 15:00 to 19:00 on Thursday, December 10, 2009, while the inset shows data from 00:00 to 04:00 on Friday, December 11, 2009 on the same mixing ratio scale. Evidently, there are much less fluctuations during the night.

A short acquisition time was also used to record a 24 hour cycle of the indoor air $\mathrm{C}_{2} \mathrm{H}_{2}$ mixing ratio in our laboratory. The indoor air was collected close to the spectrometer using the same $5 \mathrm{~m}$ long PTFE tube that was used for the outdoor air measurements. In Fig. 7, the indoor record- ings are compared to the high time resolution outdoor air data recorded on December 10 and 11. Figure 7a displays the indoor air mixing ratio measured from 12:00 on Tuesday, December 15, 2009 to 13:00 on Wednesday, December 16, 2009, whereas Fig. 7b presents the outdoor air recorded from 15:00 on Thursday, December 10, 2009 to 16:00 on Friday, December 11, 2009. In both panels, the full time resolution of one point every $70 \mathrm{~s}$ is shown.

In Fig. 8, the mixing ratios of outdoor acetylene and carbon monoxide presented in Fig. 5 are plotted versus each 
Fig. 7 Indoor air acetylene mixing ratio in our laboratory measured over 24 hours from Tuesday, December 15 to Wednesday, December 16, 2009 (a), and outdoor air acetylene mixing ratio measured over 24 hours from Thursday, December 10 to Friday, December 11, 2009 (b). In both panels, one point every $\sim 70 \mathrm{~s}$ is shown
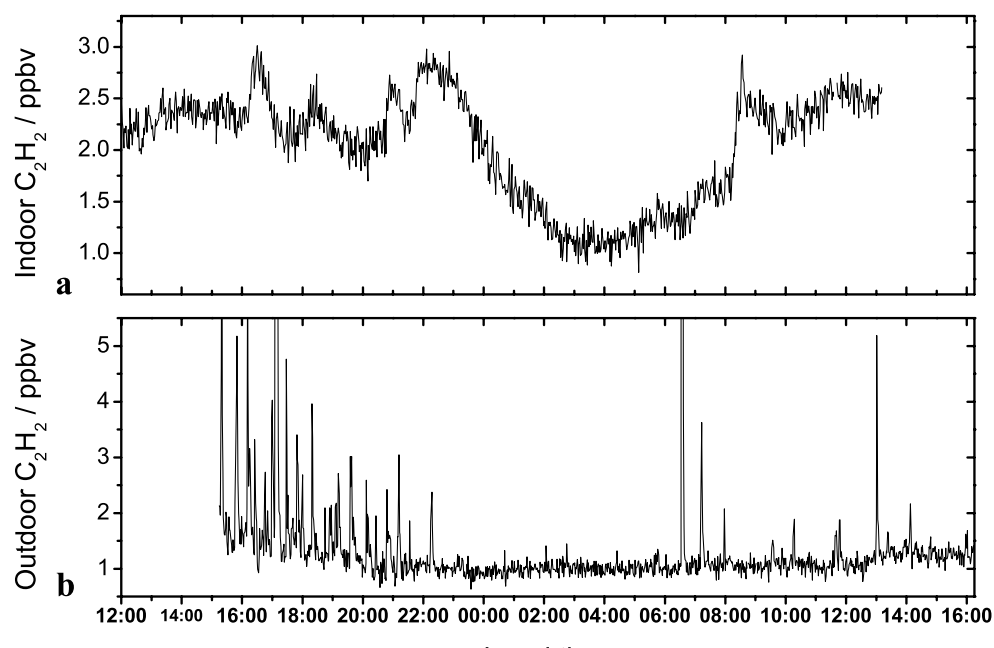

Local time

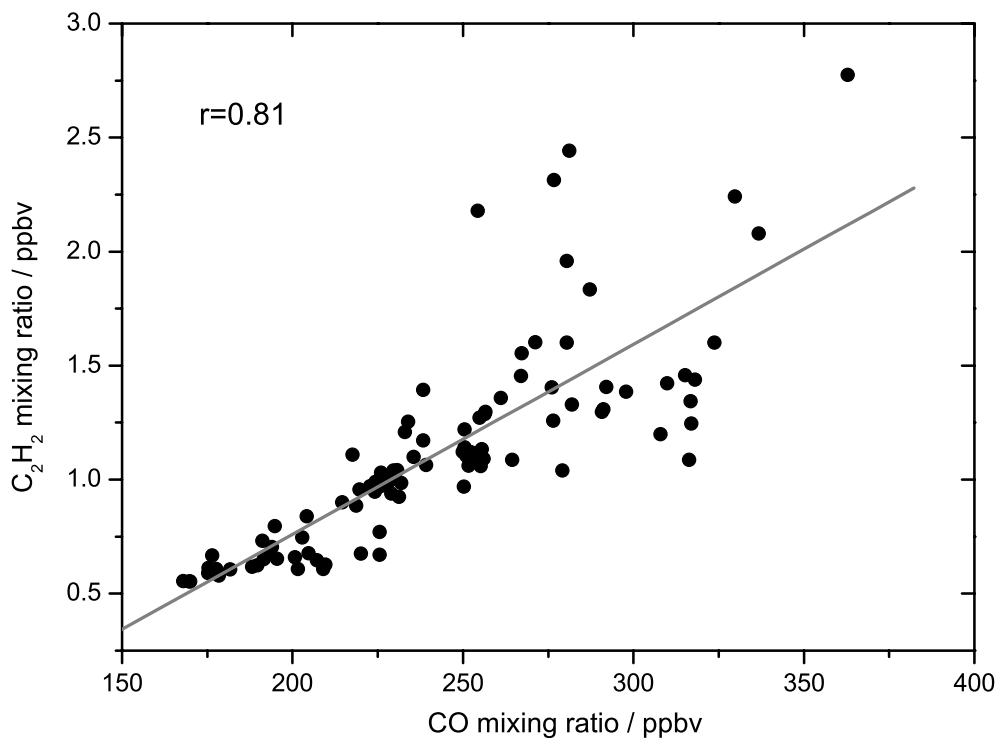

Fig. 8 Acetylene versus carbon monoxide mixing ratios for an hourly average of the $\mathrm{C}_{2} \mathrm{H}_{2}$ and $\mathrm{CO}$ data presented in Fig. $5 \mathrm{c}$ and $\mathrm{b}$. Two exceptional high $\mathrm{C}_{2} \mathrm{H}_{2}$ peaks were excluded other. Both the $\mathrm{C}_{2} \mathrm{H}_{2}$ and $\mathrm{CO}$ data were averaged with adjacent smoothing so that one point every hour was obtained for the correlation plot (solid markers). The two exceptional high peaks in the mornings of December 9 and 11 were excluded. The gray solid line represents a linear least squares fit to the data points, revealing a correlation coefficient of 0.81 .

\section{Discussion}

The high sensitivity of the CRDS spectrometer can be attributed to the high finesse cavity and the overall low-noise performance. The instrument was easy to use on a daily basis and continuous flow measurements could be performed automatically (except for refilling the liquid nitrogen trap) over several days. Although the $\mathrm{C}_{2} \mathrm{H}_{2}$ transition used for the measurements in the present work is not the strongest absorption feature in the acetylene band around $1.5 \mu \mathrm{m}$, it was the best choice for this study since there is relatively little overlap with the absorption lines of other species present in air. Accurate mixing ratio measurements with fast acquisition time could be performed even when analyzing indoor air, where increased spectral interference due to the nearby ammonia lines might occur.

The outdoor air samples collected at certain locations of interest in the Helsinki metropolitan area show somewhat lower acetylene levels (mean mixing ratio of $0.70 \mathrm{ppbv}$ ) than the indoor samples (mean mixing ratio of $1.05 \mathrm{ppbv}$ ). The mixing ratio ranges detected outdoors ( 0.37 to $1.88 \mathrm{ppbv}$ ) and indoors ( 0.49 to $2.05 \mathrm{ppbv})$ are, however, comparable. It is also difficult to find a correlation with the type of collection site. The rural samples did not have particularly low acetylene levels compared to urban or industrial samples collected on the same day. Similarly, the industrial 
samples, where elevated acetylene levels could be expected, rarely showed exceptionally high mixing ratios. Laboratory air levels can vary between 0.5 and 2 ppbv on a day to day basis (compare, for example, samples nos. 27 and 28) even at fairly constant outdoor temperatures.

The fact that we are unable to distinguish between indoor/outdoor and rural/urban/industrial samples indicates that care has to be taken with the interpretation of results obtained from single air samples collected with short filling time. Apart from the sampling location, the $\mathrm{C}_{2} \mathrm{H}_{2}$ mixing ratio also depends at least on the day of the week, the time of the day, temperature and wind direction and speed. In addition, during daytime, seemingly random fluctuations on a time scale of one to a few minutes (as revealed by the high time resolution measurements) may influence the detected mixing ratio. In our case, the process of filling the gas sampling bags with the pump took about $30 \mathrm{~s}$. This might be long enough to average out the largest fluctuations, but it can be assumed that some of the bag measurements do not show the actual baseline (or a representative average) of the acetylene level at the collection site.

Although the correlations of the $\mathrm{C}_{2} \mathrm{H}_{2}$ mixing ratios with the above mentioned parameters cannot be separated, it is interesting to note that all indoor air samples collected on December 2 show a considerably higher mixing ratio than those collected prior to that date. This correlates with a sudden temperature drop to below $0^{\circ} \mathrm{C}$ during the night from December 1 to December 2, after the temperature had been fairly constant at $6 \pm 2{ }^{\circ} \mathrm{C}$ for more than two weeks. A similar, although weaker, increase in the $\mathrm{C}_{2} \mathrm{H}_{2}$ mixing ratio starting from December 2 can be observed in Table 1 for the outdoor samples. Also, the samples nos. 7 to 9 suggest that the differences between evening (moderately high), night (low) and morning (high) can be detected with single bag measurements. The acetylene mixing ratios in public buses (samples nos. 19, 21 and 26) were always higher than regular indoor levels on the same day, probably due to exhaust gases. As expected, the air collected close to a rather busy road at Kumpula Campus (sample no. 11) showed a high acetylene mixing ratio.

Taking into account all data points shown in Fig. 5c, the mean $\mathrm{C}_{2} \mathrm{H}_{2}$ mixing ratio of the continuous outdoor air flow measurements is $1.31 \mathrm{ppbv}$, with a range of 0.48 to $58.48 \mathrm{ppbv}$. The baseline level varied between 0.5 and 2 ppbv during the 5 days of measurement. On each day, the level increased in the morning until it reached a maximum around midday before it leveled off during the afternoon and evening to a local minimum at night. A large number of moderately high peaks were detected every day between 06:00 and 22:00, most probably originating from anthropogenic sources (vehicle exhausts etc.) around the university campus. Judging from the CO data, the fluctuations of $\mathrm{C}_{2} \mathrm{H}_{2}$ on Tuesday and Wednesday should have been almost as large as on Thursday, but the low time resolution measurements missed most of these events. On Friday, December 11, the fluctuations are less pronounced in the morning and during the day. This correlates with the fact that there usually is less human activity at the university on Fridays than on other weekdays.

On some occasions, exceptional high mixing ratios of 10 to $60 \mathrm{ppbv}$ were recorded. The highest of those were observed on December 9, 10 and 11 between 06:30 and 07:00 in the morning. For a few minutes, several tens of ppbv of acetylene were present outside the laboratory. The origin of these high mixing ratios could not be identified. The high $\mathrm{C}_{2} \mathrm{H}_{2}$ (and $\mathrm{CO}$ ) mixing ratios usually lasted for $1-5$ minutes. Misleading results would be obtained from a single measurement, e.g. if a gas sampling bag would be filled in the presence of such exceptional high acetylene levels.

The mean outdoor acetylene level of $1.31 \mathrm{ppbv}$ obtained from the continuous flow measurements over 5 days corresponds well to the results of other environmental studies in comparable settings. In another study conducted in Helsinki, a mean mixing ratio of $1.66 \mathrm{ppbv}$ was measured for November 2001 using 24-h passive canister sampling [6]. An average value of $\sim 2$ ppbv over a time period of 24 hours was measured in Bristol outdoor air [24]. Somewhat lower mean values of 0.87 and $0.52 \mathrm{ppbv}$ were recorded in a smaller city [9] and a rural area [8] in France, respectively. Much higher mean levels of tens of ppbv were observed in highly populated areas $[1-3,7]$ and cities with a large number of vehicles running on biofuels [36]. Similar to our observations, the studies conducted in urban areas report wide ranges of detected acetylene levels and occasional high peak values, indicating strong fluctuations. Mixing ratios of up to 150 ppbv (hourly mean) have been observed in highly populated urban areas in the UK [37].

The acetylene baseline level shows clear differences between day- and nighttime (Figs. 5c, 6 and 7). The 4 hour period during the day presented in Fig. 6a has a mean mixing ratio of $2.1 \pm 1.8 \mathrm{ppbv}$, whereas the mean value for the 4 hour period during the night displayed in Fig. $6 \mathrm{~b}$ is $1.0 \pm 0.1 \mathrm{ppbv}$. In addition, dense and intense fluctuations were measured during daytime and evenings, but not between 00:00 and 05:00. The changes in both the acetylene baseline level and the intensity of fluctuations correlate with human activity.

Several meteorological factors, such as wind speed, wind direction and temperature, influence the detected acetylene level. A weak temperature dependence of the acetylene baseline is evident from Fig. 5c. A slight decrease in temperature in the night from December 8 to December 9 resulted in an increase in the acetylene mixing ratio baseline from $0.6 \mathrm{ppbv}$ to above $1 \mathrm{ppbv}$. The inverse temperature dependence can be attributed to the fact that the air does not mix well on cold days so that combustion related gases stay close 
to the ground where they are produced. Additional combustion sources during cold winter periods in Helsinki might be increased heating and cold vehicle starts.

Figures $5 \mathrm{~b}$ and $\mathrm{c}$ indicate a strong correlation between $\mathrm{C}_{2} \mathrm{H}_{2}$ and $\mathrm{CO}$. The correlation comprises the long-term variations during that week as well as the differences between day and night with respect to both the mean mixing ratio and the level of fluctuations. The plot in Fig. 8 confirms that a strong correlation exists for the low $\mathrm{C}_{2} \mathrm{H}_{2}$ and $\mathrm{CO}$ values, but it also reveals that the correlation becomes weaker the higher the mixing ratios are. Given the different measurement locations (a couple of hundreds of meters apart) and the fact that the $\mathrm{CO}$ data were recorded at a different height above ground $(4 \mathrm{~m})$, it is not surprising that the local variations in $\mathrm{C}_{2} \mathrm{H}_{2}$ mixing ratios do not occur at the exact same time and/or do not have the same intensity. Although not shown here, the $\mathrm{C}_{2} \mathrm{H}_{2}$ data also correlate well with the $\mathrm{NO}_{x}$ levels recorded by the SMEAR III research station.

Due to ventilation, the air in our laboratory is a dynamic mixture of indoor and outdoor air. The fluctuations observed in outdoor air therefore appear damped in indoor air and sharp mixing ratio spikes were not observed (Fig. 7). The high time resolution measurement shows how fast the baseline can increase in the morning. The indoor air acetylene level (mean mixing ratio of $2.05 \mathrm{ppbv}$ ) was generally higher than that of outdoor air (mean mixing ratio of $1.33 \mathrm{ppbv}$ ). An elevated indoor air $\mathrm{C}_{2} \mathrm{H}_{2}$ level was also found in [23] in a study involving five samples. A second study by the same authors showed comparable indoor and outdoor levels of around 2 ppbv [24]. The authors suggested that higher indoor air levels could be connected to reduced photochemical activity, and thus suppressed reactions of acetylene with $\mathrm{OH}$ inside buildings. However, the particular differences between indoor and outdoor air in Fig. 7 are most likely due to the fact that the measurements were performed on different days and at different outdoor temperatures.

\section{Conclusions}

We have demonstrated that sub-ppbv mixing ratios of $\mathrm{C}_{2} \mathrm{H}_{2}$ in ambient air can be detected without sample preconcentration using a diode laser-based CRDS instrument operating in the near-infrared region. We have further shown that our instrument is well-suited for indoor and outdoor air measurements in both static and flow conditions. An acquisition time of about 1 minute could be achieved, while retaining the required sensitivity for typical acetylene mixing ratios in air.

The measured outdoor acetylene mixing ratios have a strong dependence on the time of the day with respect to both baseline level and amount of fluctuations following the level of human activity. As can be expected for a not too densely populated urban area, baseline acetylene mixing ratios of $\sim 1$ ppbv were recorded in Helsinki during wintertime. A strong correlation of the $\mathrm{C}_{2} \mathrm{H}_{2}$ data with $\mathrm{CO}$ and a weak dependence on temperature were observed. The recordings with $\sim 1$ min acquisition time revealed intense fluctuations in acetylene mixing ratio on a minute time scale in outdoor air during daytime, with peak mixing ratios of up to $60 \mathrm{ppbv}$. While the measurements using air sampling bags in principle are accurate, the observed sudden high mixing ratios suggest that it is difficult to draw meaningful conclusions from a single bag sample, if collected as in this study. The results thus emphasize the importance of high time resolution measurements for the retrieval of accurate and reliable acetylene mixing ratios in environmental monitoring applications.

Acknowledgements The authors thank Petri Keronen and Annika Nordbo for providing the $\mathrm{CO}$ and temperature data from the SMEAR III research station. The authors are grateful to the Academy of Finland for financial support.

\section{References}

1. S. Meinardi, D. Nissenson, B. Barletta, D. Dabdub, F.S. Rowland, D.R. Blake, Atmos. Environ. 42, 7915 (2008)

2. Y. Liu, M. Shao, S. Lu, C. Chang, J.L. Wang, G. Chen, Atmos. Chem. Phys. 8, 1531 (2008)

3. E. Velasco, B. Lamb, H. Westberg, E. Allwine, G. Sosa, J.L. Arriaga-Colina, B.T. Jobson, M.L. Alexander, P. Prazeller, W.B. Knighton, T.M. Rogers, M. Grutter, S.C. Herndon, C.E. Kolb, M. Zavala, B. Foy, R. Volkamer, L.T. Molina, M.J. Molina, Atmos. Chem. Phys. 7, 329 (2007)

4. M. Kanakidou, B. Bonsang, J.C. Le Roulley, G. Lambert, D. Martin, G. Sennequier, Nature 333, 51 (1998)

5. Y. Xiao, D.J. Jacob, S. Turquety, J. Geophys. Res. 112 (2007). doi:10.1029/2006JD008268

6. H. Hellen, H. Hakola, T. Laurila, Atmos. Environ. 37, 1413 (2003)

7. B. Barletta, S. Meinardi, I.J. Simpson, H. Khwaja, D.R. Blake, F.S. Rowland, Atmos. Environ. 36, 3429 (2002)

8. A. Borbon, P. Coddeville, N. Locoge, J.C. Galloo, Chemosphere 57, 931 (2004)

9. C. Badol, N. Locoge, T. Leonardis, J.C. Galloo, Sci. Total Environ. 389, 441 (2008)

10. A.L. Swanson, N.J. Blake, E. Atlas, F. Flocke, D.R. Blake, F.S. Rowland, J. Geophys. Res.-Atmos. 108, 4065 (2003)

11. D.E. Vogler, M.W. Sigrist, Appl. Phys. B 85, 349 (2006)

12. L.D. Le, J.D. Tate, M.B. Seasholtz, M. Gupta, T. Owano, D. Baer, T. Knittel, A. Cowie, J. Zhu, Appl. Spectrosc. 62, 59 (2008)

13. R.S. Blake, P.S. Monks, A.M. Ellis, Chem. Rev. 109, 861 (2009)

14. J. Gouw, C. Warneke, Mass Spectrom. Rev. 26, 223 (2007)

15. P. Hering, J.P. Lay, S. Stry (eds.), Laser in Environmental and Life Sciences (Springer, Berlin, 2004)

16. B.A. Paldus, A.A. Kachanov, Can. J. Phys. 83, 975 (2005)

17. A.R. Awtry, J.H. Miller, Appl. Phys. B 75, 255 (2002)

18. D.S. Baer, J.B. Paul, J.B. Gupta, A. O'Keefe, Appl. Phys. B 75, $261(2002)$

19. Y. He, B.J. Orr, Appl. Phys. B 85, 355 (2006)

20. F.M. Schmidt, A. Foltynowicz, W.G. Ma, T. Lock, O. Axner, Opt. Express 15, 10822 (2007)

21. F.M. Schmidt, A. Foltynowicz, W.G. Ma, O. Axner, J. Opt. Soc. Am. B 24, 1392 (2007) 
22. A. Foltynowicz, W. Ma, O. Axner, Opt. Express 16, 14689 (2008)

23. M. Pradhan, R.E. Lindley, R. Grilli, I.R. White, D. Martin, A.J. Orr-Ewing, Appl. Phys. B 90, 1 (2008)

24. M. Pradhan, M.S.I. Aziz, R. Grilli, A.J. Orr-Ewing, Environ. Sci. Technol. 42, 7354 (2008)

25. D. Romanini, A.A. Kachanov, N. Sadeghi, F. Stoeckel, Chem. Phys. Lett. 264, 316 (1997)

26. G. Berden, R. Engeln (eds.), Cavity Ring-Down Spectroscopy: Techniques and Applications (Blackwell, Wiltshire, 2009)

27. D.W. Marquardt, J. Soc. Ind. Appl. Math. 11, 431 (1963)

28. P. Macko, D. Romanini, S.N. Mikhailenko, O.V. Naumenko, S. Kassi, A. Jenouvrier, V.G. Tyuterev, A. Campargue, J. Mol. Spectrosc. 227, 90 (2004)
29. H. Huang, K.K. Lehmann, Opt. Express 16, 15013 (2008)

30. The HITRAN 2008 database (www.hitran.com)

31. R. El Hachtouki, J. Vander Auwera, J. Mol. Spectrosc. 216, 355 (2002)

32. L. Lundsberg-Nielsen, F. Hegelund, F. Nicolaisen, J. Mol. Spectrosc. 162, 230 (1993)

33. The GEISA 2009 database (ether.ipsl.jussieu.fr)

34. The FITYK software (www.unipress.waw.pl/fityk)

35. The SMEAR research stations (www.atm.helsinki.fi/SMEAR)

36. E. Grosjean, R.A. Rasmussen, D. Grosjean, Atmos. Environ. 32, 3371 (1998)

37. The Air Quality Archive (www.airquality.co.uk/archive) 